\title{
A Case of Localized Scalp Psoriasis Triggered by Microsporum canis Infected Tinea Capitis and Review of Published Literatures
}

\section{Abstract}

We report a case in which patient was initially ill with tinea capitis infected by Microsporum canis later triggered the local scalp psoriasis. Tinea infections always confused with psoriasis, a review of published studies revealed 14 cases of fungal confused with psoriasis.

Keywords: Scalp; Lesion; Psoriasis; Spores

Received: December 16, 2016; Accepted: February 25, 2017; Published: March 03, 2017

\section{Case Report}

A 5-year-old girl presented at our clinic with 2-month history of breakage of hair associated with white scaly patches with sizes of the palm on the scalp (Figure 1). She was diagnosed as tinea capitis at the local hospital and was treated with oral terbinafine $125 \mathrm{mg}$ for 18 days and the lesion completely healed. A month after discontinuing medicine, her condition exacerbated then she continued to take oral terbinafine, but the lesion enlarged gradually. A palm size erythema with white scales with broken hair was noticed and she felt intense itch.

Circular and oval tiny spores outside of hairs were observed by direct examination with $15 \% \mathrm{KOH}$ smear of scales from the scalp (Figure 2A). Fungal culture of scales revealed light yellow filamentous colonies (Figure 2B) and microscopic examination of a slide culture showed large separated spindle-shaped spores (Figure 2C), which was consistent with the features of Microosporum canis. Genomic DNA was extracted using a DNA kit (Omega bio-tek, USA) and amplification of the intergenic transcribed spacer (ITS) regions flanking the $5.8 \mathrm{~S}$ region of the rDNA was performed by PCR. The samples were subsequently sent to Invitrogen Life Technologies for DNA purification and bidirectional sequencing. A BLAST search in GenBank using the ITS sequence showed 99\% homology to Arthroderma otae (the teleomorph of $M$. canis). The sequence has been submitted to the gene data bank and registered under the accession number of KF733019. The patient was diagnosed with tinea capitis caused by $M$. canis and treated with oral itraconazole $100 \mathrm{mg}$ and local application of naftifine and ketoconazole cream once a day for nearly 2 months, but the lesion did not heal completely,

\section{Wenying Hu,Yuping Ran, Jebina Lama and Xin Ran \\ M.D. \& Ph.D, Department of Dermatovenereology, West China Hospital, Sichuan University, 610041, Chengdu, China}

\section{Corresponding author:}

Yuping Ran

” ranyuping@vip.sina.com

M.D. \& Ph.D, Department of Dermatovenereology, West China Hospital, Sichuan University, 610041, Chengdu, China.

\section{Tel: +86 18980601697}

Citation: Hu W, Ran Y, Lama J, et al. A Case of Localized Scalp Psoriasis Triggered by Microsporum canis Infected Tinea Capitis and Review of Published Literatures. Clin Pediatr Dermatol. 2017, 3:1.

white scaly patches was also observed on the scalp (Figure 1B) but direct microscope examination and culture both negative. We carefully interviewed her family history, her mother and maternal grandfather had a history of psoriasis. She was advised for tissue biopsy which showed hyperkeratosis and parakeratosis, acanthosis with elongation of the epidermal rate ridges (Figure 3), indicated the pathology of psoriasis. Periodic acid-Schiff (PAS) and silver staining were both negative. After topical application of $0.03 \%$ tacrolimus, the patient was cured (Figure $1 \mathrm{C}$ ) after 14 days.

\section{Discussion}

Psoriasis is a chronic disease of skin, with prevalence of 2-3\% in the general population [1]. Several factors have been identified as being associated either with causation of psoriasis or with triggering exacerbations or remissions, including genetic determinants, racial and regional variation, injury and infection, cigarette smoking, alcohol, diet and other diseases [2]. In our case, first time the patient was diagnosed as tinea capitis at the local hospital and was clinical cured completely by terbinafine, then the tinea capitis recrudescence and triggered psoriasis at the same location. So our patient, the factor of psoriasis was $M$. canis infection. The mechanism of psoriasis triggered by $M$. canis infection remains to be studied. 


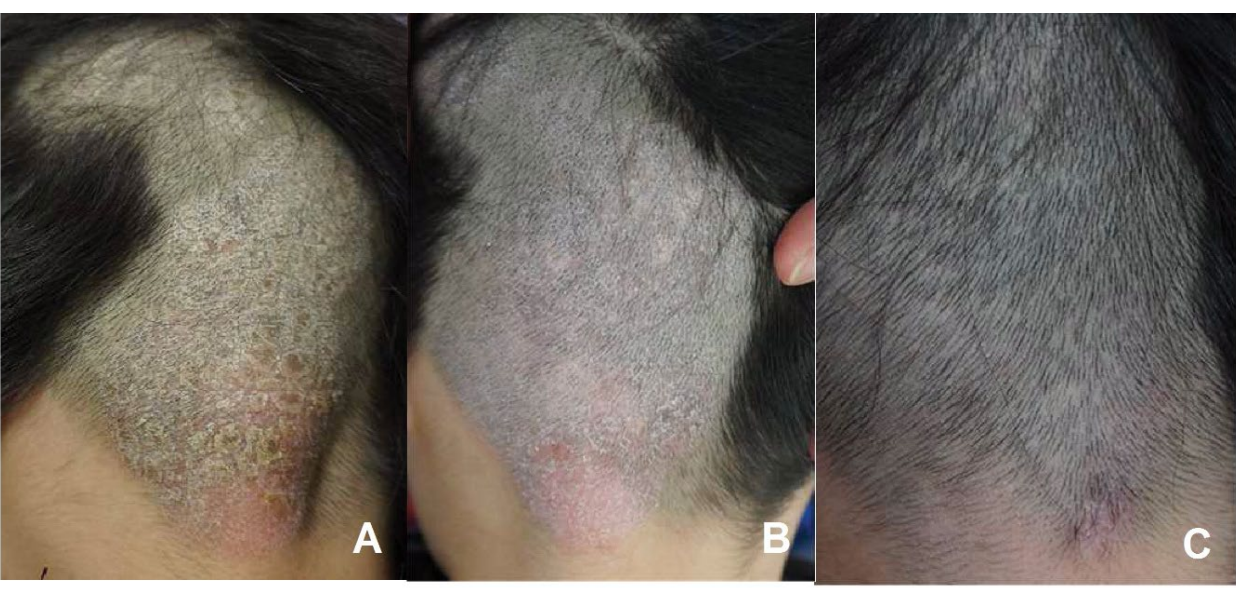

Figure 1 The clinical pictures (A. white scaly patches on the scalp. B. white scaly patches was also observed. C. the patient was cured.)

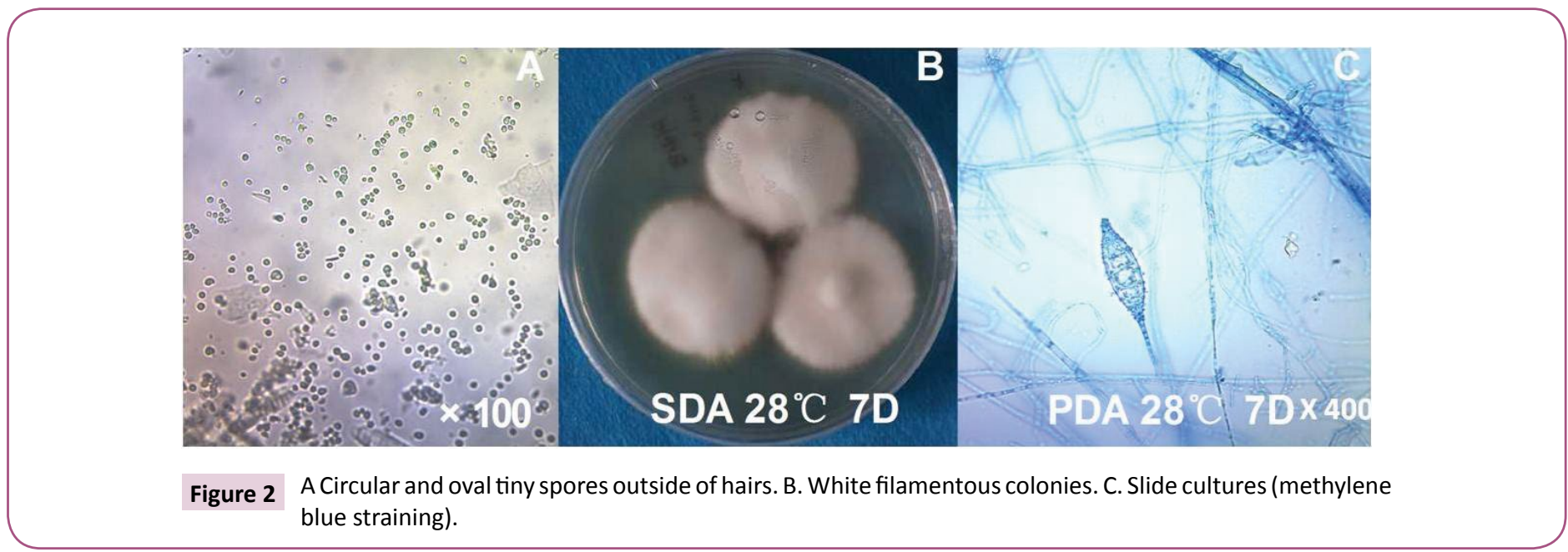

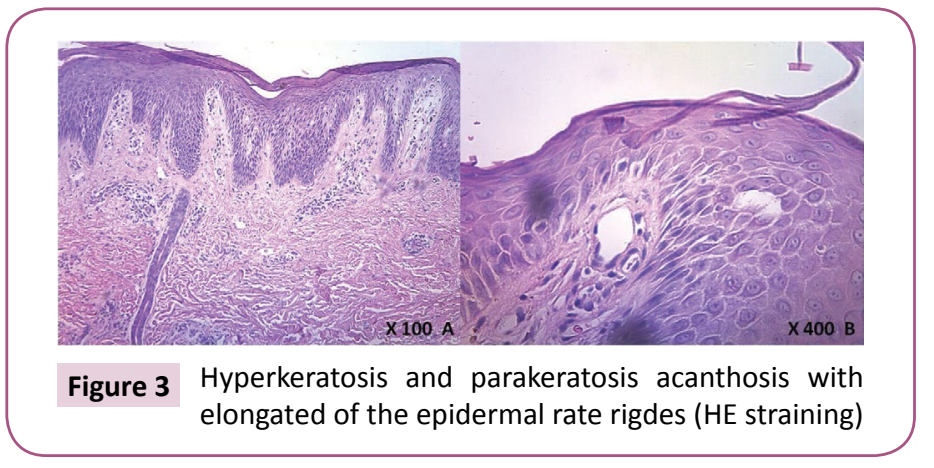

By reviewing the published papers there was few report of tinea infection induced local psoriasis but we found that the analogous presentations of psoriasis and tinea infections may cause potential confusion in the diagnosis. Fourteen cases of tinea infections confused with psoriasis are summarized in Table 1.
In summary, thirteen cases were tinea infections misdiagnosed as psoriasis, only one case was concomitant psoriasis and tinea corporis. Of the patients [3] (70\%) cases presented with psoriatic atypical signs including erythema, scales were misdiagnosed as psoriasis, [4] (15\%) cases apart from erythema but also pustular were misdiagnosed as pustular psoriasis, [5] (15\%) cases were misdiagnosed as other types of psoriasis.

By reviewing the published papers, we conclude that most cases were tinea infections misdiagnosed as psoriasis because of their analogous presentations (erythema, scales and pustular) and their similar sites, with head, face, trunk and extremities as the most common sites. It doesn't matter with their ages, sex or living areas, the most common fungus in these cases were Trichophyton rubrum and Microsporum gypseum. Itraconazole and terbinafine remain the most effective treatment choices. 
Table 1 Fourteen cases of tinea infections confused with psoriasis are summarized.

\begin{tabular}{|c|c|c|c|c|c|c|}
\hline Case & Gender & Age & Location & initiate diagnosis & Final diagnosis & Main treatment \\
\hline $1[3]$ & M & 24 & Face, trunk and extremities & Psoriasis erythrodermic & Tinea incognita & Itraconazole \\
\hline $2[4]$ & M & 45 & Left arm & Psoriasis & $\begin{array}{c}\text { Tinea incognita } \\
\text { (Trichophyton mentagrophytes) }\end{array}$ & Terbinafine \\
\hline $3[5]$ & M & 57 & Arms, torso, head, and neck & Plaque-type psoriasis & $\begin{array}{c}\text { Tinea incognita } \\
\text { (Trichophyton rubrum) }\end{array}$ & Fluconazole \\
\hline $4[6]$ & M & 63 & Head, hair loss & Psoriasis & Tinea capitis & Terbinafine \\
\hline $5[7]$ & M & 36 & Trunk, face and extremities & Psoriasis & $\begin{array}{c}\text { Tinea corporis } \\
\text { (Trichophyton rubrum) }\end{array}$ & Terbinafine \\
\hline $6[8]$ & $\mathrm{F}$ & 3 & Face and upper trunk & Pustular psoriasis & $\begin{array}{c}\text { Tinea incognita } \\
\text { (Trichophyton mentagrophytes) }\end{array}$ & Terbinafine \\
\hline 7 [9] & $\mathrm{F}$ & 22 & Eyelid & Psoriasis & $\begin{array}{c}\text { Tinea corporis } \\
\text { (Microsporum gypseum) }\end{array}$ & Itraconazole \\
\hline $8[10]$ & M & 30 & Crural regions & Pustular psoriasis & $\begin{array}{c}\text { Tinea cruris } \\
\text { (Trichophyton mentagrophytes) }\end{array}$ & Itraconazole \\
\hline $9[11]$ & $\mathrm{F}$ & 48 & Right iliac fossa & Psoriasis & $\begin{array}{c}\text { Tinea corporis } \\
\text { (Microsporum gypseum) }\end{array}$ & Terbinafine \\
\hline $10[12]$ & M & 45 & Trunk, extremities & Psoriasis & $\begin{array}{l}\text { Psoriasis and tinea corporis } \\
\text { (Trichophyton rubrum) }\end{array}$ & Itraconazole \\
\hline $11[13]$ & $\mathrm{F}$ & 11 & face, trunk and shoulders & Psoriasis & $\begin{array}{c}\text { Tinea incognita } \\
\text { (Trichophyton rubrum) }\end{array}$ & Terbinafine \\
\hline 12 [14] & M & 6 & Upper limbs and trunk & Psoriasis & $\begin{array}{c}\text { Tinea incognita } \\
\text { (Microsporum gypseum) }\end{array}$ & Griseofulvin \\
\hline 13 [15] & $M$ & 6 & Head & Psoriasis & $\begin{array}{c}\text { Tinea capitis } \\
\text { (Trichophyton schoenleinii) }\end{array}$ & Griseofulvin \\
\hline $14[16]$ & $\mathrm{F}$ & 41 & Face & Psoriasis & $\begin{array}{c}\text { Tinea incognita } \\
\text { (Microsporum gypseum) }\end{array}$ & Itraconazole \\
\hline $15^{*}$ & $\mathrm{~F}$ & 5 & Scalp & Tines capitis & $\begin{array}{l}\text { Tinea capitis (Microsporum canis) } \\
\text { triggered psoriasis }\end{array}$ & $\begin{array}{l}\text { Itraconazole } \\
\text { tacrolimus }\end{array}$ \\
\hline
\end{tabular}

* our case 


\section{References}

1 Onumah N, Kircik LH (2012) Psoriasis and its comorbidities. J Drugs Dermatol 11: 5-10.

2 Plunkett A, Marks R (1998) A review of the epidemiology of psoriasis vulgaris in the community. Australas J Dermatol 39: 225-232.

3 Huang YP, Zhou FH (2010) A case of Tinea Incognito misdiagnosed as erythrodermic psoriasis. Modern Med Health 26: 1397.

4 Liu Y, Ran YP, Zhang RF (2009) A case of unrecognized tinea corporis on the left arm that misdiagnosed for 2 years. Chin J Mycol. 4: 104105.

5 Segal D, Wells MM, Rahalkar A (2013) A case of tinea incognito. Dermatol Online J 19: 18175.

6 Joo JY, Mendese GW, Loo DS (2013) Black dot tinea capitis in an immunosuppressed man. J Clin Aesthet Dermatol 6: 49-50.

7 Gorani A, Schiera A, Oriani A (2002) Widespread tinea corporis due to Trichophyton rubrum. Mycoses 45: 195-7.

8 Kawakami Y, Oyama N, Sakai E (2011) Childhood tinea incognito caused by Trichophyton mentagrophytes var. interdigitale mimicking pustular psoriasis. Pediatr Dermatol 28: 738-9.
9 Machado AP, Hirata SH, Ogawa MM (2005) Dermatophytosis on the eyelid caused by Microsporum gypseum. Mycoses 48: 73-5.

10 Khosravi AR, Mansouri P, Naraghi Z, et al. (2008) Unusual presentation of tinea cruris due to Trichophyton mentagrophytes var. mentagrophytes. J Dermatol 35: 541-5.

11 Bhagra S, Ganju SA, Sood A (2013) Microsporum gypseum dermatophytosis in a patient of acquired immunodeficiency syndrome: a rare case report. Indian J Med Microbiol 31: 295-8.

12 Laguna C (2012) Tinea corporis in a psoriatic patient. Mycoses 55: 90-2.

13 Serarslan G (2007) Pustular psoriasis-like tinea incognito due to Trichophyton rubrum. Mycoses 50: 523-4.

14 Romano C, Asta F, Massai L (2000) Tinea incognito due to Microsporum gypseum in three children. Pediatr Dermatol 17: 41-4.

15 Khaled A, Ben Mbarek L, Kharfi M et al. (2007) Tinea capitis favosa due to Trichophyton schoenleinii. Acta Dermatovenerol Alp Pannonica Adriat. 16: 34-6.

16 Yu C, Zhou J, Liu J. (2010) Tinea incognito due to Microsporum gypseum. J Biomed Res 24: 81-3. 